\title{
Encore négocier encore
}

Il y a le signal "stop", puis la barrière flexible, enfin le mur.

Vous pouvez brûler le stop, ni vu ni connu.

Ou faire voler en éclats la barrière, quitter à abîmer votre carrosserie.

Mais, que vous le vouliez ou non, vous vous écraserez contre le mur.
Une négociation s'effectue par des échanges de propositions, contestées, refusées, oubliées, reformulées, acceptées. Un pas en avant, un pas de côté, un demi pas en arrière.

L'art est de savoir si les partenaires

- envoient un signal "danger", pour informer ou désinformer;

- s'ils dressent une barrière, en réalité flexible si on insiste suffisamment;

- s'ils édifient un mur, qui fixe la limite.

Lecteur, lectrice: la Chambre médicale a maintenant fixé ses objectifs. Nos partenaires vont devoir abattre leurs cartes. Vous êtes plus que jamais essentiels, car la force de la FMH dépend de vous et de votre détermination.

Docteur Claude Aubert, Membre du CC de la FMH 